\title{
Family institute and environmental responsibility in the view of Russian youth
}

\author{
Marina Rosenova ${ }^{1, *}$, Irina Sokolovskaya ${ }^{2}$, and Elena Tkach $^{3}$ \\ ${ }^{1}$ Moscow State University of Psychology and Education, 127051, 29 Sretenka Str., Moscow, Russia \\ ${ }^{2}$ State University of Management, 109542, 99 Ryazan Ave., Moscow, Russia \\ ${ }^{3}$ Pacific National University, 68000, 68 Karl Marx srt., Khabarovsk, Russia
}

\begin{abstract}
Modern studies of ideas about the family reflect a contradiction: on the one hand, young people are guided by the values of individualism, freedom, and self-development, and on the other, they maintain the high value and desirability of the family. The use of methods of psychosemantics and metaphorical images in the study revealed the peculiarities of young people's ideas about the family and revealed the "zones of psychological tension" in the sphere of family and family relations. In the semantics of ideas about the family, schoolchildren and students alike identified the priorities of boundaries and the understanding of the family as a closed location. In the minds of students, the cognitive and emotional aspects of ideas are more clearly differentiated, and the willingness to actively create their own family is reflected. Among young people with higher education and experience of marriage or cohabitation, negative connotations of family assessment prevail. The area of psychological stress in the family sphere: schoolchildren have a weak orientation in family relations, students have idealistic expectations, and older youth have numerous problems related to personality characteristics.
\end{abstract}

\section{Introduction}

Since the second half of the 20th century, in science and social practice, active discussions and debates have been conducted about role and value of family in the life of a modern person, liberated in his individuality. Among other things, questions are discussed on the specifics and factors that influence people's representations on family and how these representations affect real behavior and choices in the field of marriage and family relations.

It should be noted that in Russian scientific and social thought, the problem of family is actualized and has not weakened for long time. For example, 1913, sociological essay of P.A. Sorokin "The Crisis of Modern Family" caused a great resonance. In his work, the author records the emerging decomposition of the institution of family, which, however, in his opinion, will not lead to the destruction of the phenomenon of family, but will contribute to a faster transition to new forms of this social institution. The main indicators of the processes of decomposition of the usual structure of family of P.A. Sorokin states an increase in the number of divorces, while a decrease in the number of marriages and the number of children

${ }^{*}$ Corresponding author: iren3d@yandex.ru 
born in wedlock; an increase in the number of children born out of wedlock, abortion and prostitution; emancipation of women; the transformation of marriage from a religious into a secular institution, the transfer of pedagogical, educational and custodial functions to the state [1].

R.A. Levis и, G.B. Spanier, in turn, indicated as factors of the instability of marriage and family a combination of external and internal "repulsive forces", which included: decline of religious influence, formed the loyalty of society to divorce and remarriage, the simplification of divorce procedures (external forces); increasing demands of men and women for the quality of emotional relationships and connections; the need to form a balance of "proximity - autonomy" in relationships; development of the ability to change the relationship; quality of communication (internal forces) [2].

Over the past period (the second half of the 20th century - to the present), in psychology and sociology, a fairly large array of research data has been accumulated on the study of the family, in general (trends, problems), and on more specific issues, how and what people think about the family, about what are the reasons forcing people to unite, separate, or stay together, have children or adopt a strategy of conscious (rational) childlessness, register their relationship with an official authority, or be within "free relationships".

Studies by sociologists and psychologists in Russia and abroad show, still, high importance of the family as the leading value [3] and a translator of spiritual traditions. [4]

At the Congress at the Technical University of Dortmund (Germany, 2016), it was noted that the family creates, on the one hand, a resource of well-being, and on the other, acts as a risk factor: provokes gender imbalances in the upbringing and care of a child, provokes a deterioration in intergenerational ties and violation of children's rights, contains the potential for possibility of family violence. Thereupon, the important task of society is to identify possible risks and their reduction. [5] Researchers also note an advisability of including such a form of relationship as cohabitation in the study field of family and family relations [6, 7].

M. Daily, studying family change in European societies, noted a lack of readiness for parenthood, because of higher risks for women, loss of work due to the need to have more time to care a child. [8] Currently, among the modern family issues it is a remarkable problem of voluntary abandonment of birth giving, which is especially noticeable on the samples of young European men. In particular, in Germany, on average, about $28 \%$ of men and about $20 \%$ of women do not want to have children [9]. The reasons for refusing to bear children are called: the need to pursue a career and professional development, good or acceptable relation by society to the absence of children, the crisis of a monogamous marriage [10].

Even in China, a very traditional culture, displacement of family traditions are fixed from close hierarchical relationships between generations in the direction of greater freedom, democracy, equality, independence and autonomy. [11]

Russian researches show quite diverse picture of family issues. For example, in a study of the value system of 16-17 year old adolescents living in a megalopolis $(n=283)$, it was found that adolescents do not want to enter into official relations, but are ready to form a family, outside the official registration of relations; both boys and girls believe that husbands should be engaged in the material well-being of the family; adolescents value opportunities to live in love, mutual understanding and opportunities to satisfy their interests and desires; and parenthood takes a low place [12] in family happiness.V. V. Orlova and I. E. Sokolovskaya [13], studying the problems of young people, revealed that trust is the most important condition for dialogue in society; the element of trust in any relationship contains certain risks; trust acts as a constructive reaction to possible fears in making fateful decisions. In the student community, the level of trust is not sufficiently developed.Our study, described below, in a sense, helps to understand this data.

A study, carried out on adolescents from complete and incomplete families, revealed that the main differences lie in the plane of ideas about intimate-sexual relations in the family, 
the performance of household functions, social activity and external attractiveness. Adolescents from complete families, when evaluating partners are guided by personal characteristics and adolescents from disadvantaged families - by physical criteria [14].

The study of ideas on family in children who are in orphanages, or taken on the upbringing from the children's homes reflected their infantile position and orientation of the external attributiveness: for example, in family relationships, they distinguished not the relationship of family members to each other, but functional features - specific actions of "caring for a child," "cooking dinner," "cleaning the apartment," "going to the store" [15].

As you can see, the above data indicate that the institution of family and intrafamily ties, despite all the social transformations of recent decades, are an important value and a significantly desirable phenomenon in life of a person and society as a system. These facts prompted the authors to a very interesting contradiction. R. Inglehart formulated that Western rational values of "self-expression" (the importance of self-development, individuality, personal autonomy, hedonism) differ from the traditional religious values of "survival", and sometimes it is difficult to reconcile with the idea of family and marriage [16]. However, the above examples of polls show that for a modern person, who actively implements the Western rational strategy of self-expression, positioning of family and family relations is highly valuable and significant as well. It turns out that being in the current modernist situation of the contemporary world (rich with various opportunities and technologies), a person, having mastered all the available baggage, still gravitates to family, as the most stable social community. It turns out that in spite of the dynamics of global transformations in the economic and social structure, the implicit potential of positive development of family is quite high. The more valuable is any study that allows to obtain information about "subtle" psychological blockers and / or resources that allow one to overcome external and internal factors of negative influence on family systems. Therefore, the study of psychological nature of a modern person's relationships and his representations of family will make it possible to better understand and minimize the influence of "repulsive forces" (the term Levis and Spanier, but in a freer and broader interpretation).

Highlighting the problem: the above sociological and psychological studies, on the one hand, help to understand and clarify the current state of the attitude of society and its individual groups to the family and intrafamily interactions, on the other hand, this information is not enough to monitor the more subtle aspects of the existence of an individual in the family continuum. This contradiction, in our opinion, can be removed by an active study of not only obvious, rational and conscious aspects of a person's relationship to family, but also by revealing the not well realized components of family perception, which reflect the most significant aspects of social trends and psychological problems in the field of family behavior and family orientations. ...

The application of psychosemantics methods to the study of representations, relationships and perceptions of family by a modern person makes it possible to identify a phenomenological series of family images, reflecting the most significant aspects of family life and the problems of family coexistence. Such studies make it possible to reconstruct the hidden internal psychological plan of family component in life of a person (or social group).

The authors already had experience in studying the psychological representations of family image and attitudes of different groups of the population towards family life: several works have been published, reflecting the specifics of methodological approaches to research, the peculiarities of ideas about the family (in particular, among Russian women), as well as the peculiarities of the perception of family as a constraint to personal freedoms $[17,18,19]$. The presented article continues the tradition begun.

The objective of this study was to identify the semantic features of the representations about family in modern Russian schoolchildren, students and young people, and, on their basis, to determine the zones of psychological stress that can act as risks of dissatisfaction 
and disintegration of family relations and family as a system. Two "series" of studies has been conducted for that.

The field of the study was chosen representations about the family of young people in school, students, and post-student life.

The subject of study is positioned: semantic features of representations about the family of schoolchildren - older adolescents, senior students and working youth who have completed university studies.

The specificity of application of psychosemantics methods to the study of ideas of family, in our opinion, makes it possible to more accurately (in comparison, for example, with the methods of general sociology and "direct" rational psychological questionnaires) identify areas of significant stress in the field of family relations and the functioning institution of family as such ...

The presented studies were carried out by the authors at different times, but now the authors thought that to combine them into a single context is reasonable.

\section{Study methods and procedures}

As the main method, we have chosen the well-known and brilliantly proven in psychology (and not only in psychology), the method of semantic differential Ch. Osguda. This method was applied not in the classical version (12 scales distributed in the psychosemantic space of "strength", "activity", "assessment"), but in a modified extended version, which, on the one hand, is a very common research practice, and on the other hand, it allows you to identify a more specific range of problems and nuances characteristic of the studied subject area (representation about family).

The first part of the study was conducted on a group of young people aged 25-32 years, living in an urban environment of a large metropolis (Moscow), having a higher education, experience of marriage or living together with a partner in the format of family relations. The study involved 100 participants of both sexes (52 women and 48 men).

Method 1. The respondents were asked to describe the modern family using the proposed characteristics (23 pairs of antonyms), which had to be assessed in terms of the severity from 1 to 3 points (where 1 is the minimum level of expression of the characteristic, and 3 is the maximum level of expression).

The stimulus material was presented by the following scales of semantic differential (development-modification by M.I. Rosenova "Semantic differential of family description"):

1. complete - incomplete, 2. cheerful - sad, 3. heavy - light, 4. open - closed, 5. sexy non-sexy, 6. optimistic - pessimistic, 7. healthy - unhealthy, 8. changing - stable, 9. good bad, 10. calm - restless, 11. fast - slow, 12. obligatory - non-obligatory, 13 strong - weak, 14. free - not free, 15. true - unfaithful, 16. tasty - not tasty, 17. intellectual - non-intellectual , 18. open - closed, 19. stable - unstable, 20. harmonious - inharmonious, 21. cozy - not cozy, 22. flexible - rigid, 23. interesting - uninteresting.

Data processing:

The transfer of data to the final matrix was carried out in accordance with the principle of a seven-point scale:

An example of processing and record the data in the final results matrix

Table 1. Final results matrix.

\begin{tabular}{|c|c|c|c|c|c|c|c|c|c|}
\hline blank & cheerful & 3 & 2 & 1 & 0 & 1 & 2 & 3 & $\operatorname{sad}$ \\
\hline matrix & cheerful & 7 & 6 & 5 & 4 & 3 & 2 & 1 & $\operatorname{sad}$ \\
\hline
\end{tabular}


The given example allows you to get an idea of the direction of the "work" of the scales in the resulting matrix of data factorization, and the nature of the results interpretation in terms of understanding dominance of certain qualities of the description of family.

Statistical processing. The matrices of the initial results were subjected to the procedures of factor analysis (Varimax method with rotation of components), in the following variants: "for all subjects", "female sample", "male sample". The obtained factorial solutions were analyzed, the scales with the maximum factorial loads that make up the selected factors were identified, on the basis of which the resulting generalized tables of the factorial solution were compiled, with the presentation of mathematical and semantic (meaningful) analysis of these solutions.

The second part of the study was conducted on a sample of 84 people, representing a group of older adolescents 15-16 years of age (42 schoolchildren from Moscow schools) and a group of students of 4 courses (humanitarian faculties of Moscow universities), 19-20 years of age (42 people). The overwhelming majority of the study participants were representatives of complete family ( $71.4 \%$ of adolescent schoolchildren and $66.7 \%$ of students).

The family assessment method through metaphorical images was used as the diagnostic tool.

The stimulus material of the methodology is presented by 24 metaphors:

"This is a city that is to be built and maintained." "Not hell, not heaven - purgatory." "A fortress built by two lovers." "Links of the same chain that can be broken and just easy to repair." "Sunny Harbor in the ocean of life". "A fortress that will withstand any siege if there are no traitors." "Something in which everyone tries to find protection from loneliness." "Butterflies pinned down with pins under one glass." "House from the constructor: hiding is useless, protection is relative, details are the same all the time, but the house is changing. A fortress with a bunch of towers, built at different times and under construction, with many underground passages and paths." "An anchor that does not allow for tide to carry the ship, but also does not let it out to sea." "The circle have put down into polygon." "We have cheese and butter, just find some bread." "The attempt of people to live right." "A work of art among a heap of scrap metal." "The joy of life and cradle of childhood." "Hand, either open or fisted." "An anthill where everyone has their own rights and responsibilities." "Psychologically vicious circle" "Social Institute-Incubator". "Beautiful bouquet". "A traveling train with forced or planned stops at which different people enters and exit." "Needle and thread, which sometimes breaks." "The orchestra, playing the same music." "The pond with its inhabitants, who can become a swamp."

Table 2. A fragment of the methodology on semantic differential by Ch. Oscuda.

\begin{tabular}{|c|c|c|c|c|c|c|c|c|}
\hline \multirow[t]{2}{*}{ No. } & \multirow[t]{2}{*}{ "Family is...$- "$} & \multicolumn{7}{|c|}{$\begin{array}{l}\text { Evaluation } \\
\text { metaphors } \\
\text { corresponding } \\
\text { opinion }\end{array}$} \\
\hline & & 1 & 2 & 3 & 4 & 5 & & 7 \\
\hline 1 & This is a city that is to be built and maintained & & & & & & & \\
\hline 2 & Not hell, not heaven - purgatory & & & & & & & \\
\hline 3 & A fortress built by two lovers & & & & & & & \\
\hline ..... & & & & & & & & \\
\hline 24 & The pond with its inhabitants, who can become a swamp & & & & & & & \\
\hline
\end{tabular}


These metaphors were obtained in one of the studies of our colleagues, in which they asked the subjects (schoolchildren and students) to choose an image, association or metaphor for the concept of "family" (Schneider L.B., Solomatina E.M. Practical work on family psychology and family counseling. Manual. - Moscow: NEI HVE Moscow Psychological and Social University, 2012. - pp. 25-29). As a result, a "bank" of associative characteristics of the "family" concept was collected, from which we chose 24 "positions" that have the most figurative definitions.

In the Instructions for the methodology, it was asked to evaluate each metaphor in terms of how much it corresponds to the respondent's idea of the family ("what is a family, in your opinion"). The degree to which each metaphor corresponds to the respondent's idea of the family was assessed on a 7-point scale: 1 - definitely not suitable, 2 - not quite suitable, 3 not quite suitable, 4 - difficult to determine, 5 - quite suitable, 6 - quite accurately reflects my idea, 7 - absolutely suitable

Example: a fragment of the method form in Table 2.

\section{Study results}

Results of the first part of the study with modified version of the semantic differential (23 scales).

When factoring the data to entire sample, we used the factorial solution, allocated by the program itself (five factors), and for mathematical processing of the data separately for the male and female groups a 4-factor solution was initially set.

The results obtained for the entire sample (Table 3).

Table 3. Semantic features of young people 25-32 years of representations of the modern family, identified on the basis of the data factorization of structured description of the method of semantic differential $(\mathrm{n}=100)$.

\begin{tabular}{|l|c|c|c|c|c|}
\hline factors & F 1 & F 2 & F 3 & F 4 & F 5 \\
\hline \% of dispersion & $15 \%$ & $13 \%$ & $13 \%$ & $13 \%$ & $11 \%$ \\
\hline $\begin{array}{l}\text { Scales- } \\
\text { characteristics } \\
\text { with maximum } \\
\text { factor loadings } \\
\text { in the factor }\end{array}$ & $\begin{array}{c}\text { Fast (760) } \\
(-711)\end{array}$ & $\begin{array}{c}\text { Heavy } \\
(714)\end{array}$ & $\begin{array}{c}\text { Closed } \\
(-727)\end{array}$ & $\begin{array}{c}\text { Obligatory } \\
\text { (748) }\end{array}$ & $\begin{array}{c}\text { Not } \\
\text { interested } \\
\text { (-699) }\end{array}$ \\
\hline
\end{tabular}

The data in Table 3. allow us to state a fairly wide range of priority ideas of young people about modern family, as evidenced by the relative equilibrium of identified factors. The table also shows that all the presented opinions reflect not very positive characteristics of family.

Differentiated analysis of the results for the male and female samples made it possible to reveal an interesting specificity of ideas of women and men about modern family. (Table 4).

The results of the study, obtained on the male and female sample, also indicate the predominance of rather problematic characteristics in the positioning of the family by modern young educated people.

This result captures and concretizes presence of internal (psychological) threats to family institution, as the person builds their behavior based on their assessments, views and feelings. Is it any wonder that the high rate of divorces and family breakdowns in modern Russia? 
Table 4. Semantic features of the ideas of young men $(n=48)$ and young women $(n=52)$ about modern family, identified on the basis of data factorization of structured description on the method of semantic differential.

\begin{tabular}{|c|c|c|c|c|}
\hline Type of samples & \multicolumn{4}{|c|}{ Male sample $(n=48)$} \\
\hline factors & F 1 & F 2 & F 3 & F 4 \\
\hline$\%$ of dispersion & $15 \%$ & $14 \%$ & $12 \%$ & $10 \%$ \\
\hline $\begin{array}{l}\text { Scales-characteristics with } \\
\text { maximum factor loadings in the } \\
\text { factor }\end{array}$ & $\begin{array}{c}\text { Infidel } \\
(-770)\end{array}$ & $\begin{array}{c}\text { Tasty } \\
(696) \\
\text { Not interested } \\
(-604)\end{array}$ & $\begin{array}{c}\text { Heavy } \\
(807)\end{array}$ & $\begin{array}{c}\text { Sad } \\
(-784)\end{array}$ \\
\hline Type of sample & \multicolumn{4}{|c|}{ Female sample $(n=52)$} \\
\hline factors & F 1 & F 2 & F 3 & F 4 \\
\hline$\%$ of dispersion & $14 \%$ & $13 \%$ & $12 \%$ & $10 \%$ \\
\hline $\begin{array}{l}\text { Scales-characteristics with } \\
\text { maximum factor loadings in the } \\
\text { factor }\end{array}$ & $\begin{array}{c}\text { Obligatory } \\
\quad(753)\end{array}$ & $\begin{array}{c}\text { Non-sexual } \\
(-805) \\
\text { Fast } \\
(774)\end{array}$ & $\begin{array}{l}\text { Tasty } \\
(689) \\
\text { Closed } \\
(-645)\end{array}$ & $\begin{array}{c}\text { Not } \\
\text { interested } \\
(-856)\end{array}$ \\
\hline
\end{tabular}

Table 5. The generalized results of assessments of the concept of "family" given by older adolescents $(\mathrm{n}=42)$ and students $((\mathrm{n}=42)$, through metaphorical images.

\begin{tabular}{|c|c|c|c|}
\hline \multirow[t]{2}{*}{ Respondent groups } & \multicolumn{3}{|c|}{ Factors, their content and semantic generalizations } \\
\hline & Factor $1(29 \%)$ & Factor $2(17 \%)$ & Factor $3(9 \%)$ \\
\hline $\begin{array}{l}\text { Students } \\
(\mathrm{n}=42)\end{array}$ & $\begin{array}{l}\text {-Psychologically vicious circle - } \\
\text { Social incubator }(813) \\
\text {-Needle and thread, which } \\
\text { sometimes breaks }(740)\end{array}$ & $\begin{array}{l}\text {-Joy of life. Cradle } \\
\text { of childhood }(810) \\
\text { - Beautiful bouquet }\end{array}$ & $\begin{array}{l}\text { City that is to be built } \\
\text { and maintained ( } 664)\end{array}$ \\
\hline $\begin{array}{l}\text { Semantic } \\
\text { generalizations of } \\
\text { metaphors chosen } \\
\text { by students }\end{array}$ & $\begin{array}{l}\text { Limited, interconnected } \\
\text { localization, which ensures the } \\
\text { development }\end{array}$ & Ideality and beauty & $\begin{array}{l}\text { A comprehensive plan, } \\
\text { not limited to } \\
\text { implementation and } \\
\text { creation, but requires } \\
\text { efforts to preserve }\end{array}$ \\
\hline \multirow{2}{*}{$\begin{array}{l}\text { Adolescents } \\
\text { schoolchildren } \\
(\mathrm{n}=42)\end{array}$} & Factor $1(25 \%)$ & Factor $2(18 \%)$ & Factor $3(7 \%)$ \\
\hline & $\begin{array}{l}\text {-Psychologically vicious circle - } \\
\text { Social incubator (797) } \\
\text {-The pond with its inhabitants, } \\
\text { who can become a swamp ( 787) } \\
\text {-Needle and thread, which } \\
\text { sometimes breaks }(785) \\
\text {-Joy of life Cradle of childhood } \\
(-702)\end{array}$ & $\begin{array}{l}\text { A fortress with a } \\
\text { bunch of towers, } \\
\text { built at different } \\
\text { times and under } \\
\text { construction, with } \\
\text { many underground } \\
\text { passages and } \\
\text { paths(706) }\end{array}$ & $\begin{array}{l}\text { A fortress that will } \\
\text { withstand any siege if } \\
\text { there are no traitors(- } \\
661)\end{array}$ \\
\hline $\begin{array}{l}\text { Semantic } \\
\text { generalizations of } \\
\text { metaphors chosen } \\
\text { by adolescents }\end{array}$ & $\begin{array}{l}\text { Limited, interconnected } \\
\text { localization, which provides } \\
\text { development and comfort, but at } \\
\text { the risk of a negative rebirth }\end{array}$ & $\begin{array}{l}\text { Defensive structure } \\
\text { with complex } \\
\text { dynamics of } \\
\text { communications } \\
\text { and interactions }\end{array}$ & $\begin{array}{l}\text { Protection from external } \\
\text { threats, subject to the } \\
\text { reliability of the } \\
\text { constituent elements }\end{array}$ \\
\hline
\end{tabular}

The second part of the study Metaphorical descriptions of the family. 
The results, obtained on the basis of assessments, given to the concept of "family" by adolescents and students using metaphorical images are given in Table 5.

The results obtained and shown in Table 5 allow us to say that in the minds of adolescents and students, the family, the first of all, is perceived from the side of the borders: these are some localized objects filled with something (having something inside), existing to create conditions for growth ("incubator"), supplemented by the idea of connectedness ("needle and thread") and the possibilities of negative rebirth ("a thread that sometimes breaks" ; "a pond that can become a swamp"). We will analyze these results in more detail in the next section of the article.

\section{Results discussion}

The results of our study, obtained in two series, conducted using methods that are different in form, but the same in the meaningful and semantic aspect, complemented each other, and provided the identification of important psychological nuances in the ideas of adolescents, students and young people about the family, which reflect the actual zones of psychological stress of young people in the field of family and family relations. We presented the description of the results (the previous section of the article) in the chronological order of the study (first, we studied an older sample of young people who had graduated from universities for several years, and then worked with schoolchildren and students), but we will talk about the results in the opposite order, which seems more logical in terms of age.

Representations of family among adolescent schoolchildren and students.

A comparative analysis of the metaphorical semantics of the family of older adolescents and senior students has demonstrated, on the one hand, a fairly high level of similarity (perception of the family from the borders, understanding of the complexity of internal relationships, reflection of the ambiguity of quality (the possibility of negative transformations), the positivity of the assessment of the beginning of its development in the family ("joy of life, cradle of childhood", "beautiful bouquet"). On the other hand, the results obtained reflected important differences: in particular, students' understanding of the essence of family (the first factor) is separated from emotional idealization (the second factor) and their own participation-contribution (the third factor). School children - adolescents, a somewhat different picture: their understanding and emotional assessment of the family is less differentiated, merged in one factor (the first factor), and the other two factors show the already created reality (the parental family), in terms of the presence of complex intrafamily intergenerational relationships and interactions that schoolchildren may not be able to fully understand (second factor: "A fortress with towers built at different times and under construction with many underground paths and passages"), and in the aspect of understanding the family as a source of protection from external threats, but subject to the reliability of the "system elements" (third factor: "The fortress will stand if there are no traitors."

In the semantic field of schoolchildren and students' representations family, the objective age aspect associated with time perspectives was also reflected: the metaphor "a city to be built and maintained" "worked" among the students, reflecting the admissibility of intentions and the need for their own efforts in creating a family. In addition, we can judge the expanded living space of students and their inclusion of family in this large and complex space. Teenage schoolchildren do not have this. For them, the family is a predetermined limited reality ("built fortress") and a ready-made system, which is the essence of protection against the outside world, but internally complex, even with the potential of unreliability (the "risk of betrayal" is realized).

Based on the aggregate distribution of the data obtained, it can be assumed that the most pronounced zones of stress for adolescent schoolchildren in the sphere of ideas and attitudes towards the family are: 
- strictness of boundaries (rigid boundaries ("fortress") are psychologically difficult to overcome, creating obstacles to growing up, promising unification with other people and acceptance of their individuality);

- the degree of trust - distrust as to the positive development of family situation ("could become the swamp"), and in relation to the actions of individual members of the family ( "if there are no traitors");

- inadequacy of orientation in intra-family relations (there is an understanding that the system is complexly arranged "a lot of underground paths and passages").

Among students (at least in this sample), in our opinion, the main zone of tension is the presence of distinct elements of idealization in their representations of family. Taking into account the possibility that students will soon create their own family, these "idealizations" can act as the risks of the disintegration of a young family, which is reflected in Russian folklore in the expression "a love boat crashed against everyday life": such inevitable difficulties can be evaluated by young people in relation to their "idealization" is too categorical and negative, and to refuse any continuation of family relationships.

Perceptions of family among young people with higher education in the age of 25-32 years

Analyzing semantic results of assessing modern family, given by older (in relation to schoolchildren and students) young people who already have experience of marriage or cohabitation (Table 1 and Table 2), we find the advantage of negative connotations the main characteristic is "fast and weakness", followed by "heavy", "closed", "obligation" and "uninteresting". The result obtained allows us to assume that the joining up of young people into the family system occurs, apparently, on the basis of rather hasty and random (insufficiently thought out and conscious, and possibly irrelevant) choices, the consequence of which is already the "heavy", "obligation" and "uninteresting".

Differentiation of the results by gender groups made it possible to reveal the specificity of male and female ideas about modern family:

-If families in the first place for women (the first factor) are considered as a mandatory component of life, men, paramount, note the problem of infidelity (this would be recognized as the actual experience of their own behavior, and significant concerns about the prospects for the development of family relations and interactions). The result on the male sample is ambiguous, since, on the one hand, it may reflect the real state of affairs, and then this is an alarming negative property of modern family, easily explaining the increase in the number of divorces. On the other hand, it can be determined by stereotypes imposed through the media and subcultures, and / or fears and expectations, which also acts as an alarming and problematic moment.

Representation about family by men, in addition to «infidelity», painted with motifs of «heavy» and «sad», and in the women's representation sexual problems reveals (family - "not sexy" and "fast" - the second factor). If we recall that we are talking about young women (up to 32 years old), then there is an assumption about another possible and important determinant of divorce, which, most often, remains hidden from the official motivations of marital breakups.

The greatest question among the authors of the study was caused by the characteristic "tasty", which, in relation to family, was used by both men and women (the second and third factors, respectively). This is the only emotionally positive characteristic of all highlighted. It is possible that the property "tasty" refers to the real gastronomic component of family life, and it is possible that the family is perceived as a place where everything is good with food. However, the presence of another in the factor, next to this characteristic, somehow reduces optimism (for men, "tasty" is supplemented by "uninteresting", and for women - "closed"). It turns out that a possible resource that is associated with food and its rituals, reduced other emotionally-significant characteristics. 
Thus, the study of semantic component of representations about the family in young people aged 25 to 32 years old allows us to ascertain the following zones of psychological stress:

- weakness of general reflection in personality and the lack of skills to make significant decisions, with full acceptance of responsibility for them (weak differentiation of own feelings, reality and illusions, lack of understanding oneself and others, confusion of motivations, which leads to hasty non-considered actions);

- obligation to create a family, as a really existing (perhaps not very conscious) desire to justify cultural and social expectations (most pronounced among women), can be internally perceived negatively in a modern culture focused on self-expression, the development of individuality and the value of freedom of choice;

-a crisis of trust (especially in the male group): "Infidelity" reflects a lack of self-control and self-identity, serves as the basis for prejudice and fears, is a marker of unsuccessful stereotypes imposed on a person from outside (media, social networks, objective expansion of opportunities for various communication);

- crisis of creativity - the chronic presence of the characteristic "uninteresting" (in relation to the family), perhaps, reflects the situation of formed consumerism of the "they owe to me" type: consumer societies, focused on creating the widest possible opportunities in the service sector, teach a person to "take", "consume" ready-made, and even in those areas where it is necessary to make their own efforts, the principle "I am waiting for me to do well" works, and if this does not happen, a person becomes bored and uninteresting, and he himself can no longer move towards the independent creation of "interesting";

-lack intimate sexual satisfaction (found in female respondent group): the family, in this respect, is positioned by women as non sexual and fast, which most likely characterizes quality of this sphere in marital relations.

\section{Conclusions}

The conducted study allows us to formulate the following conclusions:

1.Analysis of the scientific field of research in the field of the family reveals some contradiction: despite the active development of modern culture, which put freedom of choice, individuality, self-development and self-expression on the top, which is not always easy to combine with the requirements of family life, the importance, the value and desirability of family in the system of rational preferences are found at a high level. However, this contradicts the actual problems associated with a large number of divorces (at least in the situation of modern Russia), which actualizes the search for the most accurate "targets" for prevention and creation of resource potential for overcoming the difficulties of family building by young people;

2. In the semantic field of schoolchildren and students' ideas about the family, there are many similarities (the primacy of reflection of the idea of boundaries, the phenomenon of "locality" that creates conditions for growth, and the idea of "interconnectedness"). At the same time, important differences associated with the age and socio-status characteristics of the respondents also have been found: representation of students about family is more clearly differentiated according to cognitive, emotional and active components. Students revealed the potential of the plans and actions of the independent creation of a family, and an understanding of the need for personal activity and effort is not only to create, but also the further development and maintenance of the family system. At the same time, the presence of idealized ideas about the family is noted, which can provoke disappointment and disintegration of young families, in a situation where expectations and reality do not coincide. 
The potential for activity and action plans is not traced among schoolchildren, and family is perceived as a predetermined system (built "fortress"), which has great internal complexity and functions of protection from external influences that may suffer from internal "betrayal".

-The representations of older young people (25-32 years old) are marked with the stamp of negativity associated with the assessment of family as rapidly forming, due to which it is weak, heavy and uninteresting.

Young women perceive family primarily from the side of "obligation", and young men from the side of "infidelity." For both, family appears in a closed, sad and uninteresting quality, and for women also in the aspect of sexual dissatisfaction. The gastronomic characteristic "tasty" was noted as the only positive one, which, however, still does not have a sufficient resource state, since it is associated with the negative qualities of "uninteresting" and "closed".

3. The described semantic features of ideas about the family in different age groups of young people make it possible to identify areas vulnerable to the development of the family system, or "zones of psychological stress":

- for schoolchildren, such stress zones are the problems of the severity of boundaries, lack of trust, and the weakness of general erudition in the field of family relations.

- for students, the main zone of tension seems to be excessive idealization and unrealistic expectations in the family sphere.

- older young people with higher education and experience of marriage or cohabitation reveal a whole mosaic of serious psychological stresses, mainly, in our opinion, determined by the weakness of PERSONALITY: in the aspect of ability for reflection, self-reflection and skills of making important decisions with a comprehensive assessment and acceptance of consequences, vulnerability to automatic adherence to socio-cultural normative expectations, lack of trust and abilities for proactive creativity, and (reflected in the female sample) problems in the intimate-sexual sphere.

4. Revealed semantic features of family representations and uncovered on the its basis "zone of psychological stress" in family relationships, serve to focus the attention of professionals and all educational and enlightenment institutions on the following aspects of preventive and educational work:

-of schoolchildren: on the development of a greater scientific awareness of the sphere of family relations ("forewarned - is forearmed"); on the development of ethical and communication skills, as well as the skills of autonomy and independence;

-of students: on the development of the capacity for realistic perception of yourself and other people, a realistic assessment of the objective situation;

-of youth, with higher education: to foster and promote them to genuine self-development, actively participation in additional training and / or having therapy for personal growth, training of family cohesion, the programs of communication skills improvement and building human (family) relations.

\section{References}

1. P.A. Sorokin, Modern family crisis (sociological survey), Bulletin of Moscow University. Ser. Sociology and Political Science 3, 65 - 79 (1997)

2. R.A. Levis, G.B. Spanier, Theorizing about the quality and stability of marriage. Contemporary theories about the family. W.R. Burr, R. Hill, F.I. Nye, I.L. Reiss (Eds.). Vol.1. (New York: Free Press, 1979)

3. A. Hochschild, The Managed Heart: Commercialization of Human Feeling (Berkeley: Univ. of California Press, 2003) 
4. K. Bogenschneider, Family Policy Matters: How Policymaking Affects Families and What Professionals Can Do (New York: Routledge, 2014)

5. 8th Congress of the European Society on Family Relations (ESFR) Changing Family Relations - Gender and Generations. TU Dortmund University, Germany (2016) Available at: https://www.fk12.tu-dortmund.de/cms/ESFR2016/en/home

6. M. Santoro, Cohabitation as a New Family Form in Italy: How the Meaning of Marriage Changes. Cri-sis, Critique and Change. 11th Conference Turin: University of Turin (2013)

7. A.V. Kovaleva, Transformation of the concept of civil marriage as a manifestation of the crisis of family and marriage relations: Author's abstract of dissertation to candidate in sociological sciences degree, Khabarovsk (2009)

8. M. Daly, Changing family life in Europe: Signifi cance for state and society, Journal European Societies 7, 379-398 (2005)

9. I. Seiffge-Krenke, Changes in fatherhood. Family Diversity. Collection of the 3rd European Congress of Family Science. Opladen and Farmington Hills: MI (2010)

10. F. Fiori, F. Rinesi, E. Graham, Choosing to remain childless? A comparative study of fertility intention among women and men in Italy and Britain, Available at: http://epc2014.princeton.edu/papers/140392

11. L. Wenrong, Attitudinal changes and trends of marriage and family in today 's China, Sociological Almanac (Belarus) Sociological almanac (Belarus) (2016)

12. L.I. Antonova, N.A. Tsvetkova, Family in the system of life values of 16-17 year old adolescents in a metropolis, Pedagogical sciences 1 (16), 126-128 (2006)

13. V.V. Orlova, I.E. Sokolovskaya, Confidence in conditions of social uncertainty. Innovative Technologies in Science and Education (ITSE-2020), Divnomorskoe village, Russian Federation, Edited by Rudoy, D.; Olshevskaya, A.; Kankhva, V.; E3S Web of Conferences, Volume 210, id.17034. (2020) DOI: 10.1051/e3sconf/202021017034

14. S.V. Bakhtina, A.N. Zhirova, Representations of family and marriage of adolescents from complete and incomplete families, Meridian science electronic magazine 9 (43), 180-182 (2020)

15. T.S. Bobkova, Socio-cultural representation of family and marriage from adolescents point of view in different social and educational situation of development, Kazan pedagogical magazine 5 (100), 156-163 (2013)

16. R. Inglehart, Inglehart-Welzel cultural map of the world. - Access mode: http://www.worldvaluessurvey.org/

17. M.I. Rosenova, M.A. Opiteva, Metaphors as a means of studying the cognitive models of family, Bulletin of the Moscow State University 3, 9 (2017) DOI: 10.18384/22240209-2017-3-821

18. M. Rosenova, Identification of personal freedoms in the family by Russian women and men, Man in the modern world: identity and intercultural communication. Collective monograph. Dusseldorf (2019)

19. M.I. Rosenova, M.A. Opiteva, Representations of women on the family in transitive society / Contemporary Applied Psychology: theory and practice. Collection of articles of the international scientific and practical conference (2017) 